Supporting Information

\title{
Mechanistic Investigation with Kinetic Parameters on Water Oxidation Catalyzed by Manganese Oxide Nanoparticles Film
}

Hongmin $\mathrm{Seo}^{\dagger}$, Kyoungsuk Jin ${ }^{\dagger}$, Sunghak Park ${ }^{\dagger}$, Kang Hee Cho ${ }^{\dagger}$, Heonjin $\mathrm{Ha}^{\dagger}$, Kang-Gyu Lee $^{\dagger}$, Yoon Ho Lee ${ }^{\dagger}$, Dang Thanh Nguyen ${ }^{\ddagger}$, Hyacinthe Randriamahazaka ${ }^{\#}$, Jong-Sook Lee*, and Ki Tae Nam*,†

†Department of Materials Science and Engineering, 1 Gwanak-ro, Gwanak-gu, Seoul 08826, Korea

${ }^{\dagger}$ School of Materials Science and Engineering, Chonnam National University, 77 Yongbongro, Buk-gu, Gwangju, 61186, Korea

\#Université Paris Diderot, Sorbonne Paris Cité, ITODYS, UMR 7086 CNRS, SIELE Group, 15 rue Jean Antoine de Baïf, 75013 Paris, France

\section{Supporting Information Content}

Pages: S1-S9

Figures: S1-S4

Table: S1

E-mail: jongsook@jnu.ac.kr,nkitae@snu.ac.kr 


\section{Materials and basic characterization}

\section{Materials}

$\mathrm{Mn}\left(\mathrm{CH}_{3} \mathrm{COO}\right)_{3}-4 \mathrm{H}_{2} \mathrm{O}$ (99 \%), 1-octadecene (90\%), myristic acid $\left(\mathrm{CH}_{3}\left(\mathrm{CH}_{2}\right)_{12} \mathrm{COOH}\right)$ (99\%), decanol $\left(\mathrm{CH}_{3}\left(\mathrm{CH}_{2}\right)_{9} \mathrm{OH}\right), \mathrm{Na}_{2} \mathrm{HPO}_{4}-7 \mathrm{H}_{2} \mathrm{O}$ (ACS reagent, 98.0-102.0\%), and $\mathrm{NaH}_{2} \mathrm{PO}_{4}-2 \mathrm{H}_{2} \mathrm{O}(99.0 \%)$ were purchased from Sigma Aldrich and used as received without further purification. Fluorine-doped-tin-oxide-coated glass (FTO, TEC-8) with the surface resistivity of $15 \Omega \mathrm{sq}^{-1}$ was manufactured by Pilington Company.

\section{Scanning electron microscopy (SEM)}

The morphology of the p-MnO NPs films on the FTO substrates was characterized with a high resolution scanning electron microscope (Supra 55VP, Carl Zeiss, Germany). After deposition of the MnO NPs, the substrate was gently rinsed in deionized water at least 3 times and dried with nitrogen gas. Images were taken with an acceleration voltage of $2 \mathrm{kV}$, and EDX spectra with a $15 \mathrm{kV}$.

\section{Transmission electron microscopy (TEM)}

TEM images and selected area electron diffraction (SAED) patterns were obtained using a high resolution transmission electron microscope (JEM-3000F, JEOL, Japan) with the acceleration voltage of $300 \mathrm{kV}$. To prepare TEM samples, the MnO NPs dispersed in hexane were dropped on the TEM grid and dried in air. 


\section{Estimation of turnover frequency (TOF) for $300 \mathrm{~nm}$-thickness p-MnO NPs}

The number of active sites for $300 \mathrm{~nm}$-thickness p-MnO NPs film was calculated with the assumption that all $\mathrm{Mn}$ atoms on the surface of nanoparticles serve as the active sites. The number of active sites for $300 \mathrm{~nm}$-thickness Mno NPs film was calculated by the following equation with assumption that the surface of p-MnO NPs was (100) facet. The crystal structure and lattice parameter for $\mathrm{MnO}$ were face-centered cubic structure and $4.43 \times 10^{-8} \mathrm{~cm}$.

(The number of active sites $)=(E C S A) \times\left(\right.$ the moles of $M n$ atoms $\left./ \mathrm{cm}^{2}\right)$

$$
\begin{aligned}
& =(147.8) \times\left(\frac{2}{\left(4.43 \times 10^{-8}\right)^{2} \times\left(6.02 \times 10^{23}\right)}\right) \\
& =2.502 \times 10^{-7} \text { moles } / \mathrm{cm}^{2}
\end{aligned}
$$

TOF at $1.35 \mathrm{~V}$ vs. NHE can be calculated by calculated by the following equation based on the above values.

$$
\begin{aligned}
(\mathrm{TOF}) & =\frac{(\text { current denistiy at } 1.35 \mathrm{~V} \text { vs. NHE })}{4 \cdot F \cdot(\text { the number of active sites })} \\
& =\frac{0.00496 \mathrm{~A} / \mathrm{cm}^{2}}{4 \cdot(96485 \mathrm{~A} \cdot \mathrm{s} / \mathrm{mol}) \cdot\left(2.502 \times 10^{-7} \mathrm{moles} / \mathrm{cm}^{2}\right)}=0.052 \mathrm{~s}^{-1}
\end{aligned}
$$


(a)
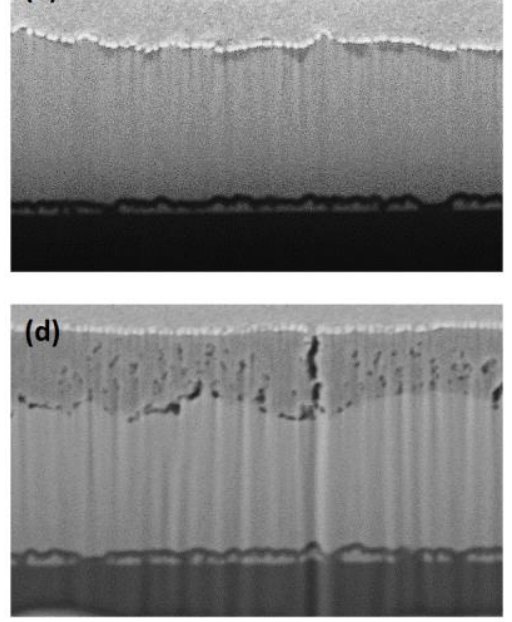

(b)
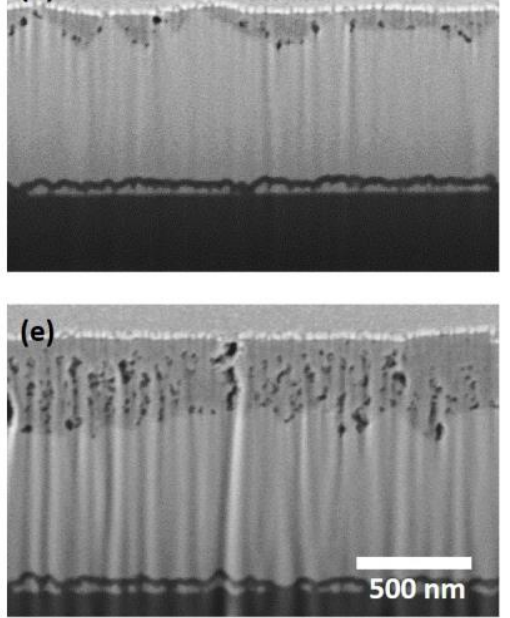

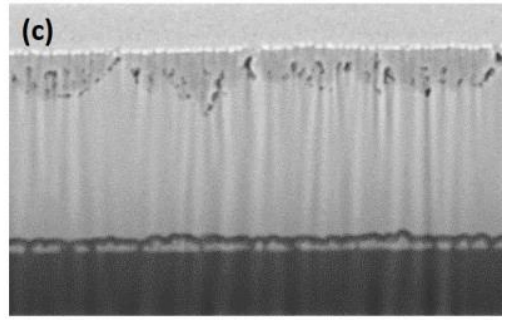

p-MnO NPs film

Figure S1. Cross-sectional scanning electron microscopy (SEM) images for p-MnO NPs films on FTO substrates for (a) $20 \mathrm{~nm}$ - (b) $70 \mathrm{~nm}$ - (c) $150 \mathrm{~nm}$ - (d) $300 \mathrm{~nm}$ - and (e) $500 \mathrm{~nm}$-thickness 

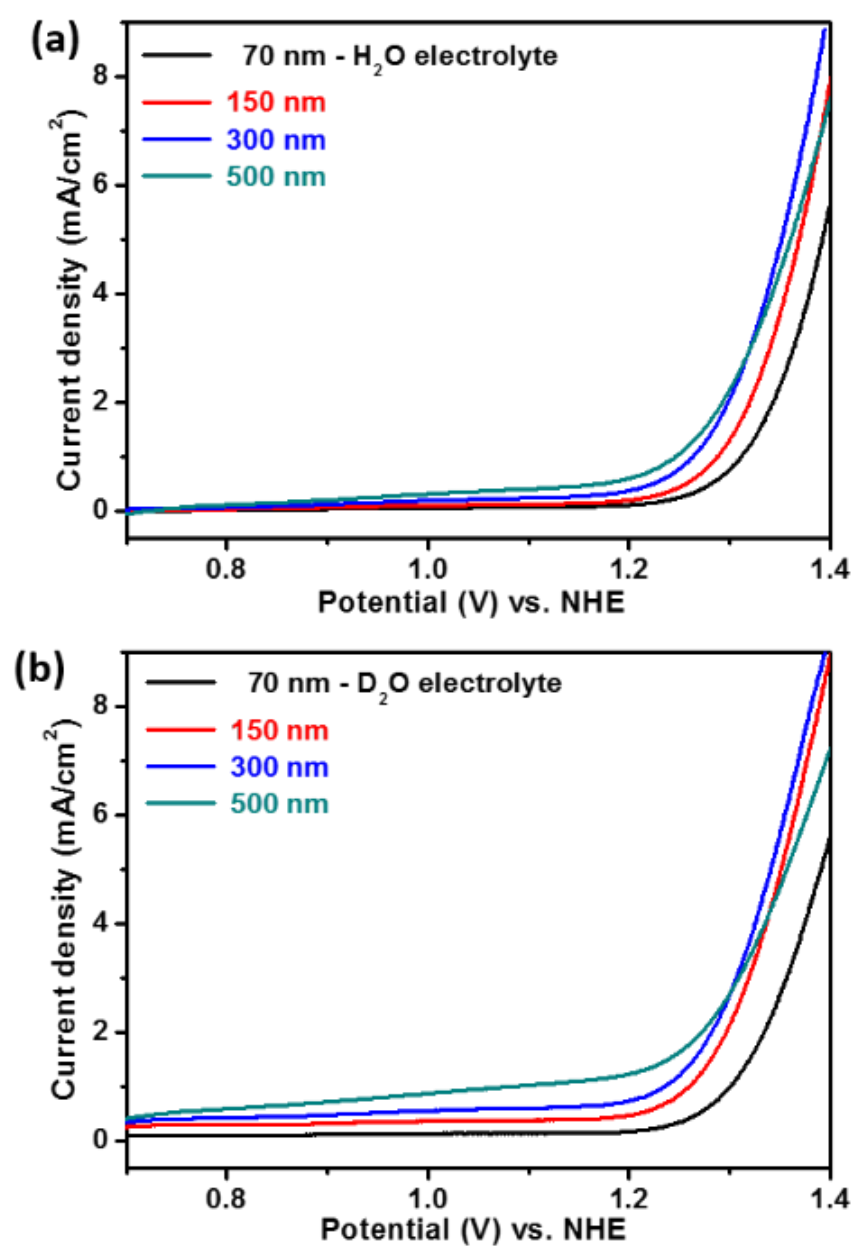

Figure S2. Polarization-corrected cyclic voltammetry curves from $0.7 \mathrm{~V}$ to $1.4 \mathrm{~V}$ vs. NHE for p-MnO NPs film of various thicknesses $(70,150,300$ and $500 \mathrm{~nm})$ at $0.5 \mathrm{M}$ phosphate buffer solution under $\mathrm{pH}$ 7. (a) $\mathrm{H}_{2} \mathrm{O}$ electrolyte (b) $\mathrm{D}_{2} \mathrm{O}$ electrolyte 


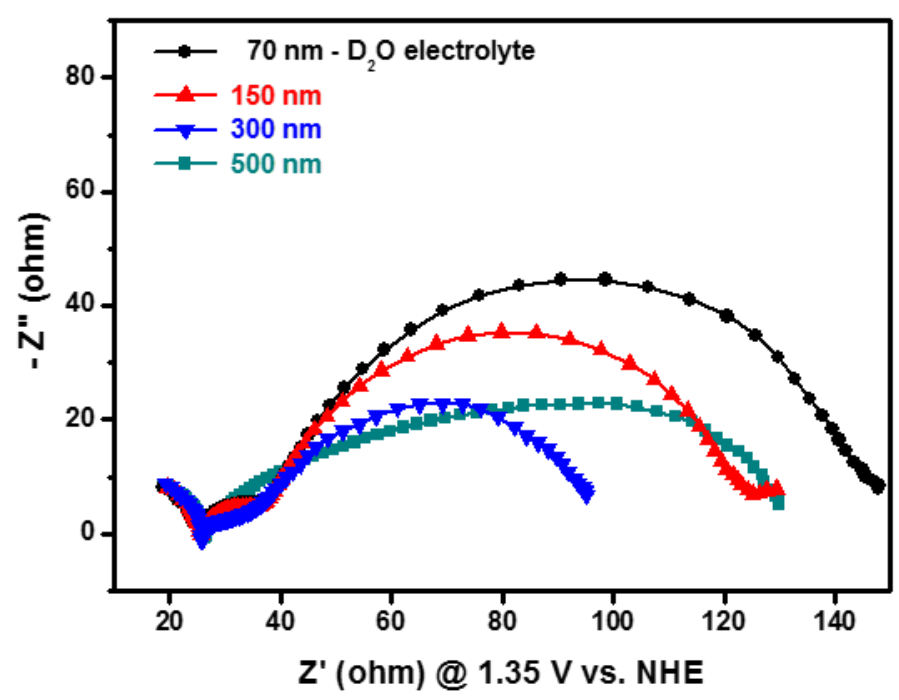

Figure S3. Nyquist plots for several thickness $(70,150,300$ and $500 \mathrm{~nm})$ of p-MnO NPs film at $1.35 \mathrm{~V}$ vs. NHE in $\mathrm{D}_{2} \mathrm{O}$ electrolyte. The black, red, blue and dark cyan spectra were for 70 , 150, 300 and $500 \mathrm{~nm}$-thickness, respectively 

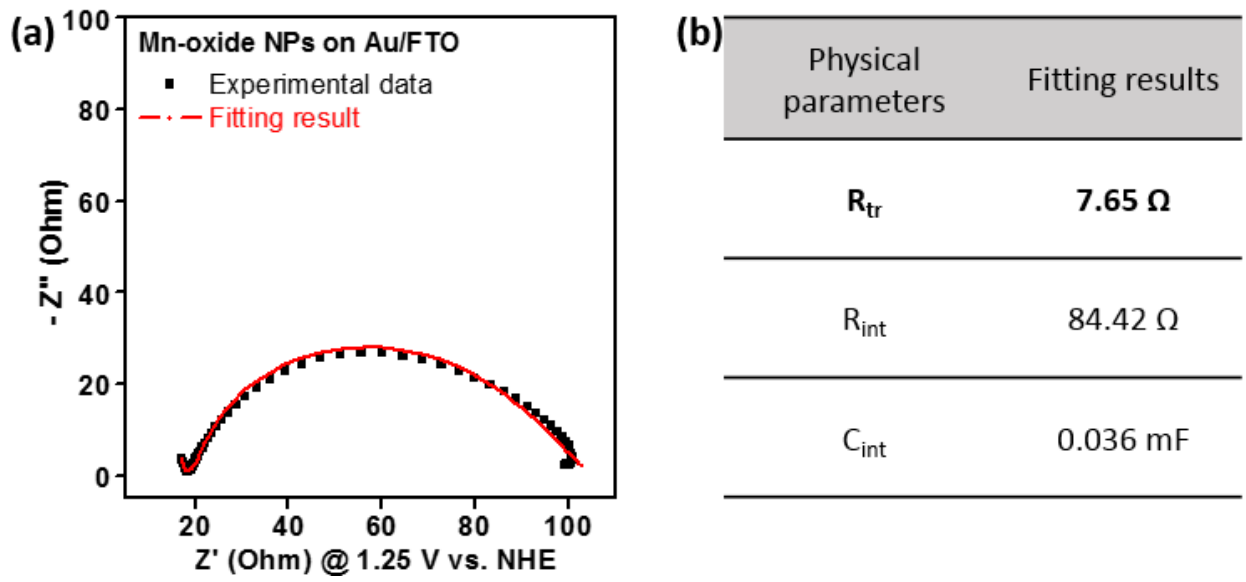

Figure S4. (a) Nyquist plot for $150 \mathrm{~nm}$-thickness Mn-oxide NPs film on Au/FTO substrates at $1.25 \mathrm{~V}$ vs. NHE in $0.5 \mathrm{M}$ phosphate buffer solution. The black dots and red line indicated experimental data and fitting result using our proposed circuit model. (b) The values for physical parameters $\left(\mathrm{R}_{\mathrm{tr}}, \mathrm{R}_{\mathrm{int}}\right.$ and $\left.\mathrm{C}_{\mathrm{int}}\right)$ from fitting with our circuit model. 


\begin{tabular}{|c|c|c|c|c|c|}
\hline Nature of Mn-oxide & Preparation method & $\begin{array}{c}\text { Mass of electroactive } \\
\text { materials }\left(\mathrm{mg} / \mathrm{cm}^{2}\right)\end{array}$ & Electrolyte & $\begin{array}{c}\text { Capacitance } \\
(\mathbf{F} / \mathbf{g})\end{array}$ & Reference \\
\hline p-MnO NPs & Spin-coating & 0.24 & 0.5 M PBS & 8.97 & This work \\
\hline $\mathrm{Mn}_{3} \mathrm{O}_{4}$ film & $\begin{array}{c}\text { Electrostatic spray } \\
\text { deposition }\end{array}$ & 0.116 & $0.1 \mathrm{M} \mathrm{Na}_{2} \mathrm{SO}_{4}$ & 150 & Ref. 1 \\
\hline $\mathrm{Mn}_{3} \mathrm{O}_{4}$ film & $\begin{array}{l}\text { Chemical bath } \\
\text { deposition }\end{array}$ & 0.57 & $1 \mathrm{M} \mathrm{Na}_{2} \mathrm{SO}_{4}$ & 193 & Ref. 2 \\
\hline $\mathrm{MwCNT} / \mathrm{Mn}_{3} \mathrm{O}_{4}$ film & Dip-casting method & 10.1 & $0.5 \mathrm{M} \mathrm{Na}_{2} \mathrm{SO}_{4}$ & 143 & Ref. 3 \\
\hline \multirow[t]{2}{*}{ Graphene $/ \mathrm{Mn}_{3} \mathrm{O}_{4}$ powder } & Hydrothermal & 2.0 & $1 \mathrm{M} \mathrm{Na}_{2} \mathrm{SO}_{4}$ & 114 & Ref. 4 \\
\hline & $\begin{array}{l}\text { Precipitation from } \\
\mathrm{MnO}_{2} \text { organosol }\end{array}$ & 0.75 & $1 \mathrm{M} \mathrm{Na}_{2} \mathrm{SO}_{4}$ & 175 & Ref. 5 \\
\hline
\end{tabular}

Table S1. Summary for reported capacitance for several Mn-oxide electrodes. 


\section{References}

1. Nam, K.-W.; Kim, K.-B., Manganese oxide film electrodes prepared by electrostatic spray deposition for electrochemical capacitors. J. Electrochem. Soc. 2006, 153 (1), A81-A88, DOI 10.1149/1.2131821.

2. Jang, K.; Lee, S.-w.; Yu, S.; Salunkhe, R. R.; Chung, I.; Choi, S.; Ahn, H., Facile Lowtemperature Chemical Synthesis and Characterization of a Manganese Oxide/multi-walled Carbon Nanotube Composite for Supercapacitor Applications. Bull. Korean Chem. Soc 2014, 35 (10), 2975, DOI 10.5012/bkcs2014.35.10.2974.

3 . Cui, X.; Hu, F.; Wei, W.; Chen, W., Dense and long carbon nanotube arrays decorated with $\mathrm{Mn}_{3} \mathrm{O}_{4}$ nanoparticles for electrodes of electrochemical supercapacitors. Carbon 2011, 49 (4), 1225-1234, DOI 10.1016/j.carbon.2010.11.039.

4. Lee, J. W.; Hall, A. S.; Kim, J.-D.; Mallouk, T. E., A facile and template-free hydrothermal synthesis of $\mathrm{Mn}_{3} \mathrm{O}_{4}$ nanorods on graphene sheets for supercapacitor electrodes with long cycle stability. Chem. Mater. 2012, 24 (6), 1158-1164, DOI 10.1021/cm203697w.

5. Wang, B.; Park, J.; Wang, C.; Ahn, H.; Wang, G., $\mathrm{Mn}_{3} \mathrm{O}_{4}$ nanoparticles embedded into graphene nanosheets: preparation, characterization, and electrochemical properties for supercapacitors. Electrochimica Acta 2010, 55 (22), 6812-6817, DOI 10.1016/j.electacta.2010.05.086. 